\title{
HISTORIA, LITERATURA Y CIENCIA EN LA EXPLORACIÓN DE LAS CAVERNAS DE CACAHUAMILPA EN EL SIGLO XIX ${ }^{1}$
}

\author{
José Alfredo Uribe Salas \\ Universidad Michoacana de San Nicolás de Hidalgo, México \\ jausalas@gmail.com \\ Laura Valdivia Moreno \\ Universidad Michoacana de San Nicolás de Hidalgo, México \\ lauravaldiviamoreno@yahoo.com.mx
}

Recibido: 18 septiembre 2014; Aceptado: 13 julio 2015.

\begin{abstract}
Cómo citar este artículo/Citation: Uribe Salas, José Alfredo y Laura Valdivia Moreno (2015), "Historia, literatura y ciencia en la exploración a las cavernas de Cacahuamilpa en el siglo XIX", Asclepio, 67 (2): p100. doi: http://dx.doi.org/10.3989/asclepio.2015.18

RESUMEN: En el presente artículo se realiza un inventario de los textos sobre las cavernas de Cacahuamilpa escritos en el siglo $\mathrm{XIX}$, desde las vertientes literaria y científica, con el objetivo de dar a conocer los enfoques con que fueron abordadas y observar la contribución de dichos documentos a la propuesta de imaginario sobre la riqueza natural de la geografía mexicana. En el aspecto literario, se observa la expresión del romanticismo mexicano y las reminiscencias de esta corriente en los viajeros enciclopédicos. En cuanto al discurso científico, es notorio el esfuerzo por estudiar el territorio, encontrar materiales explotables y discutir temas más profundos, como la edad de la Tierra o la antigüedad del hombre en América.
\end{abstract}

PALABRAS CLAVE: México; siglo XIX; cavernas de Cacahuamilpa; representación histórica; literatura; ciencia.

\section{HISTORY, LITERATURE AND SCIENCE IN THE EXPLORATION TO THE CACAHUAMILPA CAVERNS IN THE XIX CENTURY}

ABSTRACT: In this article an inventory of texts about Caverns Cacahuamilpa written in the nineteenth century is made from the literary and scientific aspects, in order to raise awareness of the approaches that were addressed and monitor the contribution of these documents at the imaginary proposal on the natural richness of Mexican geography. On the literary side, expression of Mexican romanticism and the reminiscences of this in the encyclopedic travelers are observed. As scientific discourse, it is clear the effort to study the territory, find exploitable materials and discuss deeper issues such as the age of the Earth or the antiquity of the man in America.

KEY WORDS: Mexico; nineteenth century; Cacahuamilpa caves; historical representation; literature; science.

Copyright: () 2015 CSIC. Este es un artículo de acceso abierto distribuido bajo los términos de la licencia Creative Commons Attribution-Non Commercial (by-nc) Spain 3.0. 


\section{INTRODUCCIÓN}

En México varios lugares han despertado el interés de viajeros nacionales y extranjeros, pero el que posiblemente avivó más la imaginación en el siglo XIX e ingresó al imaginario colectivo como símbolo de las riquezas de este territorio fue la caverna de Cacahuamilpa, en el estado de Guerrero. Su fama se extendió a Europa y los Estados Unidos, y pese al difícil acceso y el arduo camino para llegar, arribaron presidentes, gobernadores, políticos, cónsules extranjeros, hombres de ciencia, artistas, empresarios, mujeres distinguidas, decididos a recorrer en mulas o a pie el camino plagado de dificultades, con peligro de toparse con los forajidos que abundaban en la región.

De las excursiones realizadas existen constancias que los viajeros dejaron por medio de la pintura, la escritura y posteriormente la fotografía. De estas formas de representación, en este artículo nos interesa estudiar la documentación publicada en el siglo XIX con referencia a las cavernas de Cacahuamilpa, con la intención de abrir un espacio para reflexionar, a partir de los actores y las publicaciones realizadas, sobre la forma como fueron percibidas en el imaginario colectivo y las contribuciones que gracias a su estudio se hicieron para la Historia Natural del país.

Para ello, realizamos una recopilación de los textos que se refieren directamente a las cavernas de Cacahuamilpa desde dos vertientes: la literaria y la científica; rescatamos documentación publicada en periódicos, revistas, monografías y memorias. Como un apoyo imprescindible, revisamos las publicaciones del periodo en el acervo de la Hemeroteca Nacional de la Universidad Nacional Autónoma de México a partir del año de 1845, cuando aparece el primer registro sobre Cacahuamilpa, y hasta el año 1900.

Consideramos que el material contenido en esta base de datos es una muestra representativa de lo publicado a lo largo del siglo decimonónico en México. Se contabilizaron un total de 161 referencias $^{2}$ en el periodo señalado, en los cuales es posible observar que si bien se mantuvo la descripción de las cavernas a lo largo de esos 55 años, los discursos literario y científico variaron conforme se hizo más profunda la exploración.

En el aspecto literario, adicionalmente revisamos obras tanto independientes como de publicaciones en revistas o en periódicos, escritos en prosa o en verso sobre las grutas durante el periodo señalado, bajo la visión de que el imaginario puede entenderse como resultado de una compleja red de relaciones entre discursos y prácticas sociales; se trata de una produc- ción colectiva en la cual las sociedades esbozan sus identidades y objetivos, y se expresa "por medio de símbolos, alegorías, rituales y mitos. Estos elementos plasman visiones de mundo, modelan conductas y estilos de vida" (Baczko, 1994, p. 26).

En el discurso científico observamos un notorio esfuerzo por estudiar el territorio, encontrar materiales útiles para la economía y discutir temas más profundos, como la edad de la Tierra o la antigüedad del hombre en América. También se realizaron aportes al estudio de la Historia Natural en México, particularmente sobre la flora y fauna de las cavernas y de la región, su geografía, geología, paleontología y arqueología, sin olvidar que en otras latitudes el estudio temprano de esta caverna por parte de Dominik Bilimek es considerado uno de los primeros de tipo bioespeleológico, no solamente en México sino también en el mundo (Gunn, 2004, p. 307).

Por otra parte, nos percatamos de que las cavernas de Cacahuamilpa pueden ser consideradas un microcosmos de lo que acontecía en el país, puesto que en la historia larga del siglo XIX se hace referencia a ellas en distintos acontecimientos de la vida política, cultural, económica, social y turística del mismo. Sin embargo, en este artículo se profundiza en las dos vertientes señaladas, y se da una breve reseña de esto último.

\section{CACAHUAMILPA. UBICACIÓN Y DESCRIPCIÓN}

La región norte del actual estado mexicano de Guerrero, que colinda con Morelos, está conformada por cerros calcáreos, en su mayoría de origen marino. Geológicamente, se distinguen tres sistemas independientes de grutas y ríos subterráneos: el del cerro de la Estrella, situado en el centro del valle; el del cerro de Acuitlapan o del Tepozonal, ubicado próximo al extremo sur del valle; y el Sistema de Cacahuamilpa, que comprende "los cerros Gigante, Jumil y Cerro Grande o de la Corona, constituidos por calizas cretácicas (Formación Morelos) y lutitas calcáreas del Cretácico Superior" (Bonet, 1965, p. 26).

La gruta denominada Cacahuamilpa, la de Carlos Pacheco y los cursos subterráneos de los ríos Chontalcoatlán y San Jerónimo se encuentran en el cerro La Corona, como si estuvieran divididos en dos pisos: en el inferior los cursos de los ríos y en el superior, las dos grutas (Bonet, 1965, p. 26, 28).

La caverna de Cacahuamilpa está ubicada al oeste del meridiano $99^{\circ} 30^{\prime}$ y al norte del paralelo $18^{\circ} 39^{\prime}$, a $2000 \mathrm{msnm}$. Se trata de una sola galería pero, debido a estalagmitas y trozos desprendidos de la bóveda, da 
la impresión de estar dividida en varias salas, que los visitantes han nombrado de acuerdo con sus características y cuyos nombres han variado con el paso de los años: 1. El Chivo o del Pórtico; 2. De los Confites; 3. Del beso o de los enamorados; 4. La Aurora; 5. La trompa de elefante; 6 . Del Negrito; 7. De las cortinas; 8. De los tronos; 9. Los querubines; 10. Los panteones; 11. Plaza de armas; 12. Del pedregal del muerto; 13. Puerto del aire; 14. De Dante; 15. De la mujer dormida; 16. De los cirios; 17. De la pila bautismal; 18. De las palmeras; $y, 19$. De la gloria y el infierno.

\section{BREVE HISTORIA DEL LUGAR}

El pueblo de Cacahuamilpa, cuyo nombre significa en náhuatl "sementera de cacahuate" (Orozco y Berra, 1855, p. 415) se encuentra en el actual municipio de Pilcaya, Guerrero. En 1533, los frailes agustinos recién llegados a la Nueva España buscaban aquellos espacios en que franciscanos y dominicos todavía no habían instalado misiones, para realizar su labor evangelizadora, de modo que arribaron a esta región (Piho, 1991, p. 14). Se tiene registro de que el padre fray Agustín de la Coruña y el P. S. Esteban Ilegaron a la provincia de Chilapa el 5 de octubre de 1533, por órdenes del padre fray Francisco de la Cruz, para continuar la propagación de la religión católica. Una vez ahí, fundaron y cuidaron más de 20 parroquias, entre ellas la de Cacahuamilpa, ubicada en la entonces provincia de México (Orozco y Berra, 1855, p. 115).

En 1823 dieron inicio los esfuerzos de los ex insurgentes Nicolás Bravo y Juan N. Álvarez para crear una nueva entidad en la zona sudoccidental del país, pero fue hasta el 27 de octubre de 1849 cuando mediante Acta Constitutiva se conformó el nuevo estado - denominado Guerrero-, con municipios que habían pertenecido al Estado de México, Puebla y Michoacán. El gobernador interino fue Juan N. Álvarez, quien después sería ratificado en su puesto, vía elecciones. La zona donde se encuentra Cacahuamilpa pasó entonces a formar parte de la nueva entidad (INEGI, 1997, p. 50; Uribe Salas, 2008).

Se atribuye el descubrimiento de la primera caverna de Cacahuamilpa a Manuel Sainz de la Peña Miranda, rico propietario de Tetecala, quien la conoció cuando los indígenas de la región lo ocultaron en ella durante una persecución (García Cubas, 1874, p. 147). Cabe mencionar que al decir descubrir, hacemos referencia al momento en el cual comenzó a difundirse su existencia, pues como se ha dicho, los indígenas de la región tenían conocimiento de ellas y, al parecer, Vicente Guerrero también las había utilizado durante la Independencia.
Lo cierto es que una vez develada su existencia, acudieron a conocerlas personalidades como: la marquesa Calderón de la Barca, la emperatriz Carlota, pintores nacionales y extranjeros, presidentes de México como Ignacio Comonfort, Sebastián Lerdo de Tejada y Porfirio Díaz-; gobernadores de Morelos y Guerrero; diplomáticos, políticos, militares y, por supuesto, naturalistas que trataron de estudiarlas, clasificarlas, explicar su origen y definir su antigüedad. Gran parte de los viajeros dejó constancia de su visita ya fuera por medio de una descripción del lugar o tallando su nombre en el interior de la gruta. El geógrafo Antonio García Cubas relata que cuando acompañó al presidente Sebastián Lerdo de Tejada en 1874, este último encontró la inscripción de doña Carlota, que decía: «Carlota llegó hasta aquí", y talló él mismo: "Sebastián Lerdo siguió adelante" (García Cubas, 1904, p. 626).

Otro de estos viajeros fue el periodista y escritor Cecilio Robelo, cuyas descripciones de la caverna se publicaron tanto en España como en México, contribuyendo de manera decidida a su internacionalización. Para él, las expediciones más notables realizadas en Cacahuamilpa hasta el año de 1886, en que las exploró, son las siguientes:

- 1835: La expedición exploradora compuesta por el barón de Gros, secretario de la Legación Francesa en México, don Manuel Velázquez de la Cadena, el barón René Pedreuville y don Ignacio Serrano, dibujante de la expedición.

- 1837: Mariano Galván, autor de los calendarios³.

- 1850: Los profesores de la Academia de San Carlos.

- 1855: El presidente de la República, general Ignacio Comonfort.

- 1865: La emperatriz Carlota.

- 1869: El general Pedro Baranda, primer gobernador del estado de Morelos.

- 1874: El presidente de la República, Sebastián Lerdo de Tejada.

- 1879: Expedición científica compuesta por los ingenieros Mariano Bárcena, Miguel Iglesias y Gumesindo Mendoza, acompañados por los generales Carlos Pacheco, Jesús Lalanne, Jesús H. Preciado, Ángel Martínez y Feliciano Chavarría, y los señores Francisco Bulnes, el coronel Francisco Ramírez y Eugenio Cañas, entre otros.

- 1881: El presidente de la República, general Porfirio Díaz, acompañado de sus ministros, los 
señores generales Carlos Pacheco, J. Treviño, Lic. I. Mariscal: del cuerpo diplomático, de los generales Ord y Frisbie y de otras personas «notables» (Robelo, 1886, p. 2$)^{4}$.

\section{Cacahuamilpa en la prensa de México}

Cuando en 1834 se dio a conocer la existencia de una gruta enclavada en la sierra, que posiblemente sería más bella y más grande que la famosa caverna de Mammouth, en Estados Unidos, algunos voltearon la vista hacia el pequeño pueblo de Cacahuamilpa. Además del espectáculo natural, probablemente quienes acudieron primero lo hicieron en busca de minerales para explotar o de "guano», un fertilizante natural muy apreciado en esa época (Cortés Zavala y Uribe Salas, 2014). Los viajeros registraron sus experiencias por medio de escritos que fueron publicados en periódicos, revistas e incluso formaron libros independientes, que las dieron a conocer no sólo en México sino también en Europa y los Estados Unidos.

La primera referencia que se tiene de la caverna en la prensa nacional corresponde al año 1845 y se trata de una pequeña mención a la misma, en la parte final de la descripción de los alrededores de Cuernavaca, firmada por Fidel -pseudónimo del político y escritor liberal Guillermo Prieto- en la Revista Científica y Literaria de México (Fidel, 1845, p. 125). La ausencia de registros anteriores a ese año nos hace suponer que durante la primera década posterior a su descubrimiento, la principal difusión sobre esta caverna fue realizada a través de monografías de los primeros viajeros y por medio de la expresión verbal. En la figura 1, se observa la frecuencia de publicaciones sobre Cacahuamilpa por año, contenidas en la Hemeroteca ya mencionada ${ }^{5}$.

Al observar el continuum de lo escrito en la prensa, encontramos que en esos 55 años se hicieron 161 referencias directas o indirectas a Cacahuamilpa, entre noticias, descripciones, anuncios y comentarios, lo cual nos da un promedio de 2.92 por año. Estos registros tienen tres puntos destacados, que a su vez se vinculan con sucesos políticos, naturales y económicos, respectivamente: la excursión del presidente Sebastián Lerdo de Tejada a la gruta en 1874; los derumbes o hundimientos en las proximidades de Cacahuamilpa en 1879; y la utilización de las cavernas como símbolo del país ante intereses económicos extranjeros y nacionales.

En el terreno de la política el hecho más trascendente en el periodo fue el viaje del presidente Sebastián Lerdo de Tejada en 1874, como puede apreciarse en el Gráfico 1, donde se observa que dicho año tiene la mayor cantidad de registros, con 59 referencias directas encontradas, mismas que están encaminadas en tres direcciones: la reseña del viaje, la crítica a la figura del presidente por ausentarse de sus funciones y la parte científica de la expedición. Esta profusión de notas sobre el tema es explicada en el periódico El Siglo Diez y Nueve, del 4 de marzo de 1874, de la siguiente manera:

Este incidente de la visita a Cacahuamilpa, ha dado margen á una prolongada polémica en la prensa, en la cual por más tiempo y papel que se haya gastado no han logrado los gobiernistas poner el hecho bajo un aspecto favorable, pues se los impide la terminante prescripción del artículo 84 de la Constitución, que solo permite la salida del presidente por motivo grave, y no lo es ciertamente el de una partida de placer proyectada cuando no pesaban aún sobre el señor Lerdo las sérias atenciones á las que hoy debe dedicarse con incansable afán?

Los ataques fueron publicados por el político, escritor y general Vicente Riva Palacio en el periódico El Radical. Por su parte, en los argumentos esgrimidos en defensa del presidente se dio peso a las ventajas científicas que este viaje tendría y que pronto podrían verse publicadas, dado que en la expedición habían participado naturalistas como Mariano Bárcena y el geógrafo Antonio García Cubas, quienes realizaron informes científicos que fueron publicados a la brevedad (Valdivia, 2013, p. 97). Esta justificación muestra el peso específico del tema científico en el discurso, en vísperas del último cuarto del siglo XIX, al destacar estos resultados junto con otros de carácter político, como la destitución del gobernador del estado de Morelos y la reconciliación entre el político liberal y magistrado de la Suprema Corte Ignacio Manuel Altamirano y el gobernador del estado de Guerrero ${ }^{8}$.

Por su parte, el viaje del presidente y general Porfirio Díaz en 1881 no recibió tanta atención por parte de la prensa, pese a que llevaba numerosos invitados - entre los que destacaba el ministro de España-, orquesta y otros acompañantes. Además, cabe destacar que para la ocasión fue instalada, en forma temporal, energía eléctrica en la caverna (Robelo, 1886, p. 2).

El segundo acontecimiento que recibió mayor cantidad de menciones por parte de la prensa fue el capítulo de los hundimientos o resbalamientos de terrenos cercanos a la gruta, dado que ocupó 15 de las 21 menciones que hubo en 1879. Tras una lluvia torrencial y un «fuerte terremoto» algunos terrenos inmediatos al 
Figura 1. Frecuencia de menciones en la prensa escrita desde 1845 a 1900

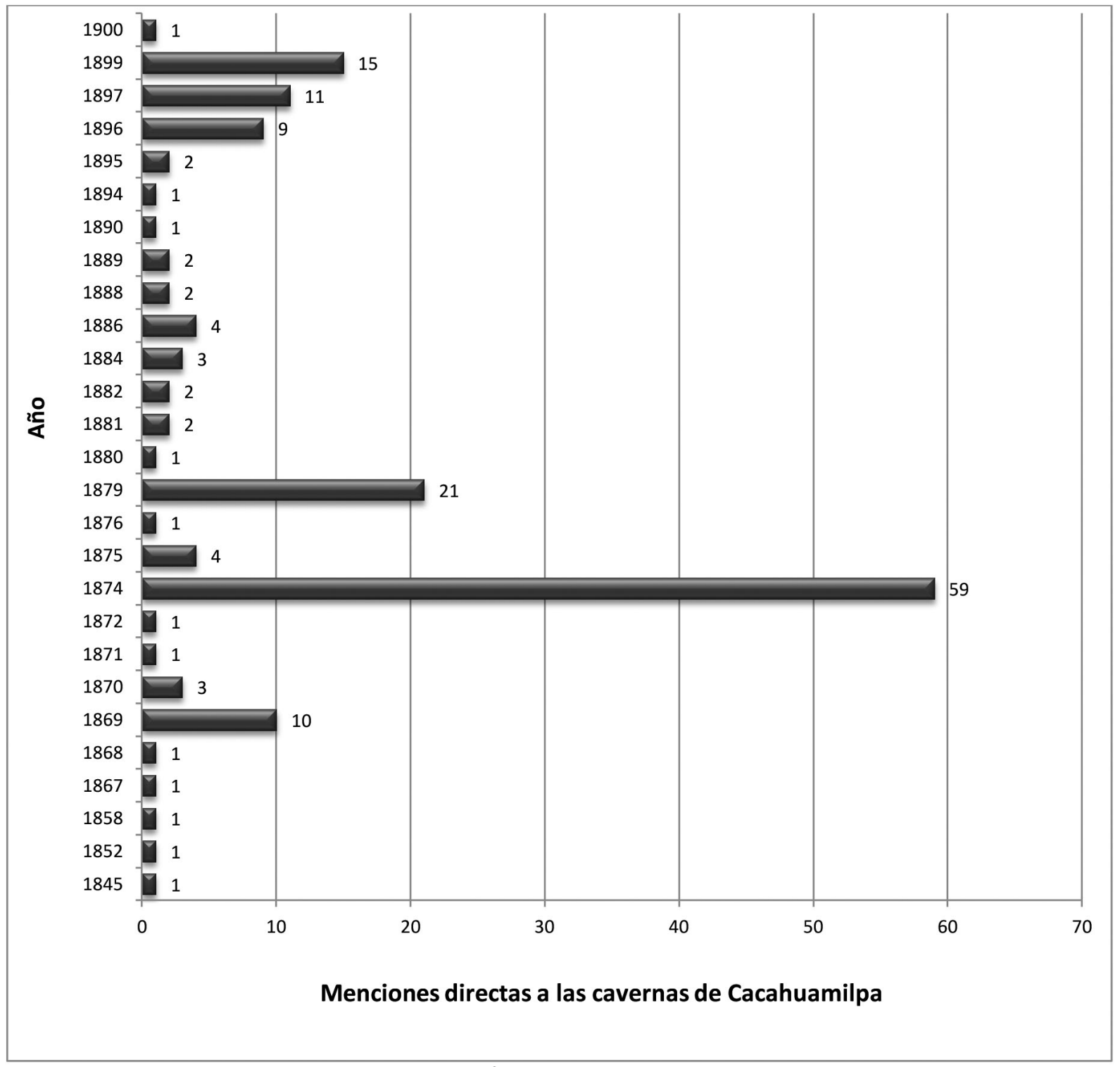

Fuente: Hemeroteca Nacional Digital de la UNAM, 1845-1900.

poblado de Cacahuamilpa se hundieron, de modo que se solicitó la participación de los hombres de ciencia del país para que realizaran un estudio que descartara posibles daños o peligros en la caverna.

Las menciones en prensa se deben al seguimiento de la expedición que acudió a revisar los daños, encabezada por Mariano Bárcena, en un afán por mantener al lector informado sobre los resultados de las pesquisas y la posibilidad de perder una de las joyas naturales más famosas del país. Esta expedición, sin embargo, arrojó nueva información sobre el lugar, dado que se descubrió la segunda caverna, ubicada a unos cuantos metros de la primera, misma que recibió el nombre del general Carlos Pacheco, quien había acompañado a la expedición y a quien se dice que los indígenas de la región revelaron su existencia9 ${ }^{9}$.

Los registros que ofrece la prensa evidencian que el foco de las grutas estuvo en la simbiosis entre el interés científico por explorarlas y el económico por obtener algún beneficio de su explotación. En las postrimerías del siglo el conocimiento emanado de la lectura y la curiosidad por conocer las grutas ya eran utilizados para atraer la atención de los extranjeros, de modo que fungieron como símbolo o re- 
presentación de la riqueza del país. Incluso se realizó una reproducción de la caverna que se pretendía llevar a la Exposición de París en 1900 y que fue utilizada para decorar el edificio del $\mathrm{H}$. Ayuntamiento en la Ciudad de México, para la recepción de los médicos que participaron en el Segundo Congreso Médico Pan Americano en 1896, con sede en este país ${ }^{10}$.

Explotar en forma adecuada las grutas se requería inversión en infraestructura adecuada para recibir a los visitantes, como carreteras, hoteles, electricidad dentro de las cavernas e incluso un ferrocarril interior para recorrerlas sin tanta fatiga. Como solución se constituyó en 1896 la Sociedad Explotadora de las Grutas de Cacahuamilpa, Sociedad Anónima, que apoyada por el gobierno realizaría las mejoras:

Se ha formado una sociedad anónima para explotar las célebres grutas de Cacahuamilpa, tan admiradas por los turistas. En ese hermoso sitio, prodigio de la naturaleza, se va á llevar a cabo, próximamente, la instalación de la luz eléctrica, colocándose en las diversas grutas, y de manera proporcional, 200 luces de arco y 600 incandescentes, cuyo material está ya dispuesto.

Además, para que los visitantes puedan admirar mejor las bellezas de las grutas, se construirá en el interior de éstas un ferrocarril ad hoc, y una carretera desde Cacahuamilpa hasta el punto donde ordinariamente hace escala el Ferrocarril Interoceánico.

Las mejoras citadas deben quedar concluidas, á más tardar, para septiembre próximo, pues el señor Presidente de la República piensa visitar las grutas en unión de los congresistas médicos norteamericanos, que llegarán a México á mediados de dicho mes. ${ }^{11}$

Sin embargo, parece que la recién formada Sociedad Explotadora no alcanzó a terminar los trabajos, dado que en lugar de llevar a los médicos a Cacahuamilpa, se encontró la forma de llevar Cacahuamilpa a los médicos, como ya se mencionó.

\section{Otras referencias en la prensa}

Hubo noticias a destacar sobre las grutas, que si bien no recibieron la atención de las ya mencionadas por parte de la prensa y del público, revisten importancia para la historia del lugar, como la nota del 6 de julio de 1858 en el periódico La Sociedad, que informa que la Comisión de Arqueología nombrada en la Sociedad Mexicana de Geografía y Estadística, contemplaba entre sus primeras proposiciones solicitar a Xochicalco, Cacahuamilpa y Taxco vigilancia, para evitar la destrucción de los antiguos monumentos en sus respectivas demarcaciones.

Por otra parte, en las páginas de los diarios puede verse cómo en el imaginario colectivo ya ha incorporado la visión de la caverna como un lugar donde es fácil perderse o "enredarse», dada su extensión, que se creía era mucho mayor de la que en realidad posee. Una muestra de lo anterior aparece en el periódico EI Padre Cobos del 13 de mayo de 1869: "¿En qué se parece el gobierno á la gruta de Cacahuamilpa?-En que tiene mil enredijos» ${ }^{12}$.

\section{CACAHUAMILPA COMO OBJETO LITERARIO}

La belleza de las grutas de Cacahuamilpa ha despertado desde tiempos prehispánicos la imaginación de quienes se han adentrado en ellas. Leyendas sobre personas que se han perdido o que han encontrado refugio en este lugar, mitos relacionados con rituales de tipo religioso, han persistido en la memoria colectiva hasta nuestros días y, junto con las posteriores descripciones que han hecho viajeros y exploradores, las han vuelto recurrentes a punto tal que, como ya se dijo, en el siglo XIX fueron capaces de simbolizar la belleza, la abundancia y el misterio del país.

La leyenda más arraigada de origen prehispánico es aquella donde un jefe depuesto hizo que su hija desconocida interpretara, en la gruta de Cacahuamilpa, el papel de una deidad para reclamar, exitosamente, el retorno de su padre como líder del pueblo (Nosari, 1899, p. 27). Otra, más reciente, trata sobre un explorador inglés que al buscar fama y fortuna ingresó a la caverna acompañado solamente de su perro, pero ya nunca salió con vida; el can fue a buscar ayuda para su amo, pero como nadie comprendió lo que quería, regresó a morir su lado. Años más tarde unos exploradores los encontraron y los enterraron ahí mismo, dando así nombre al Salón del Muerto.

Quienes primero escribieron sobre las grutas fueron, por supuesto, los viajeros que iniciaron el trayecto hasta ellas. El escenario en que se desarrollaban estas exploraciones coincide con años realmente difíciles para la nueva nación mexicana. Las disputas por el poder y por la definición del país que se deseaba, sucedidas entre distintos bandos - republicanos y realistas, conservadores y liberales-, acarrearon dificultades en todos los órdenes del gobierno. Esto se refleja en las formas de expresión que se adoptaron, y que coincidieron con la corriente romántica, que llegó a México a inicios del siglo y se hospedó en la Acade- 
mia de Letrán (1836-1856), donde a diferencia de Europa convivieron, sin mayores enfrentamientos, autores románticos con neoclásicos (Carabés, 1998, p. 21).

El movimiento adquirió en este país características propias: además de la preponderancia del sentimentalismo, el interés por lo exótico, lo sobrenatural y la muerte, así como la exaltación de la belleza y la naturaleza, se tuvo como característica el nacionalismo, de modo que bajo esta impronta se produjo literatura consciente y dirigida hacia el progreso, aspecto que comulgaba bien con los ideales de libertad e identidad que propalaban los liberales. Fue más adelante, con el denominado segundo romanticismo, cuando alcanzó su máximo desarrollo, con escritores como Guillermo Prieto, Ignacio Manuel Altamirano, Francisco Zarco, Juan de Dios Peza, entre otros, en el Liceo Hidalgo -formalizado en 1849-. Estos autores buscaban establecer un sentido de nacionalismo por medio de la descripción del territorio y de sus costumbres (Perales, 1957, p. 78).

Por otra parte, hubo viajeros europeos que siguieron la senda marcada por Alexander von Humboldt y llegaron al país que el sabio describió en su Ensayo político sobre el reino de la Nueva España como pródigo en riquezas que esperaban su explotación. Al realizar sus viajes y retornar a sus países de origen, promovieron el conocimiento de la gruta de Cacahuamilpa entre los suyos, con lo cual también se dio la necesidad de orientar a los nuevos exploradores por medio de guías de viaje (Martínez, 2011, p. 76, 78).

De la conjunción entre romanticismo y viajeros al estilo Humboldt se derivaron obras que abarcaron, e incluso traspasaron, distintos géneros. Entre los escritores del periodo que realizaron al menos una obra sobre Cacahuamilpa destacan: Francisco Zarco, Cecilio A. Robelo, Marco Arróniz, Pedro Robles, José Tomás de Cuéllar, Elvira Nosari; también personas cuyo oficio no era escribir pero por su posición fueron leídos, como madame Calderón de la Barca y el pintor romántico Eugenio Landesio. De igual forma, desconocidos que después de visitarlas se animaron a enviar una carta a un amigo o un familiar, para describirlas, y que fueron publicadas en periódicos de la época. Para el caso que nos ocupa, destacan la literatura de viajes, la narrativa, la poesía y la literatura científica.

\section{Literatura de viajes}

La literatura de viaje o de viajeros recoge la necesidad de contar lo que se mira por primera vez, lo que resulta fascinante y se desea transmitir:
Un libro de viajes es, esencialmente, un libro descriptivo: se trata de fijar en la imaginación y en la memoria del lector una serie de elementos que hasta entonces le son ajenos. Para ello se recurre a la descripción, a la acumulación de rasgos caracterizadores que a través de la semejanza o de la oposición van conformado una imagen captable y asimilable por el lector (Pierini, 1990, p. 119).

Actualmente, y en parte gracias a los estudios desde la historia cultural, ha cobrado auge en Europa y en España el estudio de este género o subgénero literario (Alburquerque, 2011), pero en el siglo XIX los relatos de viajes eran consideradas inferiores en comparación con la novela o la poesía, y junto con «diarios, epistolarios, biografías y traducciones, quedaron reducidas a simples 'intermediarios', es decir, como ocasionales puntos de contacto entre distintos conjuntos culturales» (Cita de Gnisci, 2002, p. 145, en Martínez, 2008, p. 281).

Entre quienes escribieron relatos de viaje hacia Cacahuamilpa en el siglo XIX se encuentran tres mujeres: la marquesa Calderón de la Barca, la emperatriz Carlota y la profesora Elvira Nosari. Sus textos se ubican, cronológicamente, pocos años después del descubrimiento de la primera caverna, en la parte intermedia del siglo y a finales del mismo, respectivamente.

Frances Erskine Inglis (1804-1882) -mejor conocida como madame Calderón de la Barca- llegó a México el 12 de diciembre de 1839 acompañando a su esposo, el marqués Ángel Calderón de la Barca, primer ministro plenipotenciario de España en este país. Producto de su correspondencia durante los dos años que permaneció en territorio mexicano, publicó en 1843 un libro denominado Life in Mexico during a Residence of two years in that country, en Boston, mismo que dos meses después fue editado también en Londres (Bono, 2002, p. 155-194).

En él describe, bajo su óptica, los paisajes de nuestro país y sus costumbres, entre ellos a la región de Cacahuamilpa. Su libro se difundió en Europa, Estados Unidos - donde residía su familia, migrante de Escocia- y España, principalmente. En México recibió críticas o fue ignorado por literatos de su tiempo como Ignacio Manuel Altamirano o Manuel Payno, porque consideraron que expuso algunos defectos de la cultura mexicana (Bono, 2002, p. 158); sin embargo, en la parte donde se refiere a Cacahuamilpa, su narración deja salir el asombro que sintió en este lugar, y mientras menciona su recorrido por las distintas salas, llega a la conclu- 
sión de que la caverna es indescriptible - «Unfortunately, it is indescribable» (Calderón de la Barca, 1970 , p. 313).

Durante el Segundo Imperio (1863-1867) en México -específicamente en 1865-, Carlota de Bélgica (1840-1927), esposa del archiduque Maximiliano de Habsburgo, realizó a caballo el recorrido a Cacahuamilpa en 1865. En la descripción que escribió sobre este viaje, narra cómo quedó asombrada por los paisajes que pasó en el camino, a punto tal que describe los pueblos de Coatlán del Río y Acapatzingo como "los más hermosos que yo había nunca visto» (Iturriaga, 1992, p. 322). De Cacahuamilpa nos dice: «También visité la hermosa cueva de Cacahuamilpa, una de las maravillas de este continente y puse mi nombre más allá del de Comonfort y de muchos otros, no quisiendo [sic] que el Imperio se quedara atras [sic] tampoco allá» (Iturriaga, 1992, p. 322). Sin embargo, al salir de la caverna le informaron sobre la muerte de su padre, el rey belga Leopoldo I, y su alegría se convirtió en pena.

Existen pocas referencias a la profesora Elvira Nosari ${ }^{13}$, pero sabemos que estudió en la Normal, fue profesora en la ciudad de Toluca y escribió al menos dos obras de teatro bajo su nombre verdadero, y otros textos y tratados bajo el pseudónimo de Mario Dill (Collet, 1995, p. 130). Ella publicó su relato «Un viaje a Cacahuamilpa», también de género epistolar, en el periódico El Mundo del 21 de mayo de 1899 y en un pequeño librito del mismo nombre y en ese mismo año (Nosari, 1899).

Las tres mujeres, en distintos momentos de la exploración a Cacahuamilpa, mostraron su admiración por el lugar. Las tres eran cultas, educadas en Europa - aunque se desconoce si al momento de hacer el viaje Elvira Nosari ya había ido a estudiar en Roma a la Institución de María Montessori (Collet, 1995, p. 130-131) - y las tres utilizaron figuras lingüísticas como la comparación y la metáfora para describir el lugar, aunque con temor de no lograrlo de manera adecuada, como expresa Nosari: Nos dice: «...a pesar de que siempre he sido atrevida para todo lo que es escribir, tratándose de Cacahuamilpa tengo miedo; miedo de decir poco y de rebajar á tus ojos aquellas bellezas que ni las plumas orientales sabrían reproducir» (Nosari, 1899, p. 3).

La marquesa Calderón de la Barca fue más allá, al decir que no había nada con lo que la caverna se pudiera comparar. Sin embargo, vislumbra que a futuro será un «lugar de espectáculo»:
Some day, no doubt, this cave will become a show-place, and measures will be taken to render the approach to it less dangerous; but as yet, one of its charms consists in its being unhackneyed. For, long after, its recollection rests upon the mind, like a marble dream. But, like Niagara, it cannot be described; perhaps even it is more difficult to give an idea of this underground creation, than of the emperor of cataracts; for there is nothing with which the cave can be compared (Calderón de la Barca, 1970, p. 317) ${ }^{14}$.

Como ya se dijo, los hombres letrados que tomaron sus plumas para bosquejar la caverna del recién formado estado de Guerrero, lo hicieron con la intención de perfilar una identidad mexicana a través de la descripción de costumbres, paisajes y cultura, como una forma de nacionalismo. Este nacionalismo se tradujo en obras de viajeros como las escritas por Francisco Zarco y Cecilio Agustín Robelo, quienes decididos a cambiar la imagen negativa que algunos extranjeros llevaban en sus textos hasta otros países, escribieron con los objetivos ya comentados.

Francisco Zarco (1829-1869) publicó «La caverna de Cacahuamilpa» en Presente Amistoso Dedicado a las Señoritas Mexicanas, del 10 de enero de 1852; se trata de una publicación dirigida a las mujeres, por lo cual las menciones al Creador son constantes. De la misma manera, puede observarse la maestría del escritor al emplear la metáfora y la comparación:

Ya se descubren soberbias torres, grandiosos castillos, altísimas montañas blancas que parecen coronadas de nieve, árboles colosales de piedra, tumbas y mausoleos, figuras extravagantes, risueñas, sombrías... Unas veces nos creemos entre las ruinas de un castillo de la edad media, otras en medio de un panteón y sobre los túmulos parece que los muertos se levantan con sus sudarios, otras las formas de las rocas son tan bellas como si hubiera una vegetación de piedra que produjera flores y hojas colosales (Zarco, 1852, p. 435).

De la literatura de viajes se desprende un subgénero -o quizá ya un género nuevo- popularizado en Europa durante el siglo XIX por las editoriales Baedeker y Murray, en Alemania e Inglaterra, respectivamente, y que se separa de los otros relatos en tanto que sirve para facilitar a los viajeros su travesía: las guías de viajeros. Los mexicanos se aprestaron a escribir sobre su país como una forma de contrarrestar los escritos de los extranjeros donde se presentaba una imagen no deseable, de 
modo que entraron en forma temprana a participar en este género, que poco a poco se fue definiendo (Martínez, 2011, p. 78).

Desde esta trinchera escribió el poeta romántico Marco Arróniz (1828 o 1830-1858), quien en 1858 publicó en París su "Manual del viajero en México», en cuya introducción se explican los motivos por los cuales fue escrito:

...solamente quisimos presentar á la vista del viajero todo lo que pudiese interesarle, y estuviera en relación con lo útil y pintoresco; refutando con ejemplos irrecusables á esos autores que se han ocupado ligeramente y con malevolencia de nuestra querida patria, la que, sean cuales fueren sus errores y desgracias, merece un tributo de admiración y respeto del mundo civilizado (Arróniz, 1858, p. V).

Como puede apreciarse en las páginas de esta guía, el tono que se utiliza es informativo, pues aunque no deja de utilizar figuras como la comparación o la metáfora, se describe en forma más objetiva y se proporcionan datos lo más exacto posible - para ese tiempo- de posición geográfica, caminos, transportes disponibles, entre otros. En su Capítulo VI. Curiosidades de la República, comienza con la descripción de la caverna Cacahuamilpa, pues como dice:

Nada es tan digno de ocupar el primer lugar en este capítulo como la famosa Caverna de Cacahuamilpa, porque es la obra mas bella con que la naturaleza ha adornado á nuestra patria ... debemos considerarla como la primera en su género, y llamarla Emperatriz de todas las cavernas... (Arróniz, 1858, p. 257-258).

Este manual, publicado en París, pondera la caverna de Cacahuamilpa como el más bello lugar de la República. La objetividad con que habla de ella es tal, que insiste en llamarla caverna y no gruta o cueva, y hasta se detiene a explicar el porqué de esta denominación (Arróniz, 1858, p. 266).

Por su parte, en 1866 Cecilio A. Robelo (1839-1916), miembro del Liceo Hidalgo, sigue este mismo camino al publicar en La América, periódico de España, un artículo que, debido a su tratamiento, puede considerarse una guía de viaje hacia Cacahuamilpa (Robelo, 1866, p. 14-15). Un mes después, se publicó también en México, en La Patria del 7 de febrero.

\section{Narrativa}

Deseamos destacar la novela Los plateados de tierra caliente, episodios de la Guerra de Tres
Años, firmada por Perroblillos - pseudónimo de Pedro Robles) y publicada en 1891, debido a que abre un intermedio en la narración - todo el capítulo IV - para introducir íntegro un relato de viaje de Eugenio de Jesús Cañas (1848-1923), sobre su visita a la caverna de Cacahuamilpa. La descripción que realiza este autor es más completa que las anteriores, en tanto que se remonta en la historia hasta la fundación del mismo pueblo; de la misma manera, proporciona datos geográficos sobre los lugares que van pasando, referidos no solamente a los aspectos de la naturaleza, sino también a la población, las construcciones y los plantíos que dejan atrás en su camino.

Cuando se adentran a la gruta, la narración continúa mostrando un alto grado de conocimiento del lugar, obtenido gracias a que Cañas acompañó a Mariano Bárcena en su expedición científica de 1879.

Internémonos por fin en ese dédalo sombrío, entre cuyas negruras se levantan, se confunden, blanquean a trechos, visibles a la luz solar que débilmente penetra en el primer salón, la multitud de monumentos de todas formas, unos distintos, los más cercanos; otros vagos, indeterminados, fantásticos.

Este primer salón se llama del Chivo; debe su nombre a aquella estalagmita, de cerca de un metro de altura, la primera a la izquierda entrando, que remeda harto imperfectamente la forma de aquel rumiante; hoy está mutilado; antes que los entusiastas turistas llevaran como recuerdo de su excursión fragmentos de él, merecía mejor su nombre. La altura media de veinticinco a treinta metros que tiene la bóveda es la misma que conserva hasta el cuarto salón con algunas alternativas; su ancho varía entre cincuenta y cien metros hasta el mismo cuarto salón.

Perdida en la oscuridad, a la izquierda, y casi al comenzar a subir la falda de esa especie de montaña que divide el primer salón del segundo, la cual está formada de gradas cóncavas que en la estación de lluvias están desbordando agua purísima, hay una grandiosa estalagmita que generalmente pasa desapercibida por los visitantes; alumbradla, pero mucho, porque es muy alta y necesita verse en conjunto; es un monumento espléndido (Cañas, 1887).

A pesar de ser una novela, nos crea la idea de ser un "croquis» o un plano de las grutas en el cual vamos atravesando, sólo imaginando la belleza del lugar, pero observa que era necesario estudiar y cuidar este espacio. 


\section{Poesía}

«En las grutas de Cacahuamilpa» es el título del poema que José Tomás de Cuéllar (1830-1894) declamó durante la visita del presidente Porfirio Díaz a la caverna de Cacahuamilpa en 1881 (Cuéllar, 1856, p. 172-177). Inspirado en el paisaje e influenciado por la corriente romántica, la mayoría de sus versos relacionan de manera clara las grutas con la muerte o con la tumba - por su oscuridad y frialdad-; pero al mismo tiempo compara las estalactitas y estalagmitas con seres míticos griegos de gran belleza - sílfides-, de modo que en ese momento de tristeza y soledad también la felicidad está presente, porque el poeta puede estar con su sentimiento y lejos del bullicio que aturde:

Esta es mansión de paz, donde no suenan

del loco mundo aterradores gritos;

los pensamientos que la mente llenan,

son pensamientos del Señor, benditos.

El aire frío en el peñón no zumba,

todo está quieto, solitario, inerte:

iel funeral silencio de la tumba!

Sin embargo, su mente le crea conflicto en la penumbra, imagina seres aterradores y situaciones mortales entre la carmín iluminación de las teas. La rebeldía de su espíritu lo llevó hasta ahí, y al encontrarse en zona tan peligrosa sabe que es igual de necesario este ímpetu para el país que se está conformando y del cual él forma parte.

El orgullo por la belleza irreal y aterradora de las grutas se hace presente, es el amor, la fascinación y el temor por la inmensidad de lo desconocido y al mismo tiempo tan propio. Esa gruta es el alma del poeta y la de la patria, los dos en la búsqueda de la luz.

¡ESPLÉNDIDA mansión, recinto umbroso

de silencio y de paz augusto templo:

de tu imponente majestad ansioso,

extático y absorto te contemplo!

(..)

Este es el lugar de tétricas visiones

con que delira el mísero poeta;

con sus gigantes pálidos peñones,

con su aura muda, perezosa, quieta...

(..)
Hay más autores de la literatura nacional e internacional que se inspiraron en este espacio para crear sus obras y recrear con estilos literarios diversos la majestuosidad que los cinco sentidos captaban al adentrarse en ellas. Pero es más constante, como puede observarse, el simbolismo manifiesto de la esencia del país que se erigía salpicado por los acontecimientos de cada época, desde los prehispánicos hasta la modernidad porfiriana de finales del siglo XIX. En el imaginario social se magnificó su sobriedad pero también su grandeza; su origen bíblico en contraposición de fuerzas externas que habían actuado desde siempre; se buscaron los recursos naturales en la profundidad de sus cavidades y al final su utilidad fue para la recreación y el turismo de aventura que alcanzó gran popularidad desde entonces.

\section{EL INTERÉS CIENTÍFICO POR CACAHUAMILPA}

El interés por las cavernas de Cacahuamilpa que mostraron naturalistas, geógrafos y geólogos mexicanos y extranjeros en el siglo XIX, mucho tuvo que ver con las teorías que llegaban de Europa, ya que veían en ellas el universo propicio para sentir, describir, medir y explicar el origen y sentido bíblico de los accidentes naturales o las fuerzas físicas que provocaban accidentes geográficos y geológicos de esa magnitud. Para unos, su majestuosidad y belleza era obra divina, para otros, los menos, el resultado de causas más terrenales que operaban al margen de la religión y la política, pero que había que conocer para explicar.

A lo largo del siglo XIX muchos fueron los intereses que movieron la curiosidad de individuos y grupos por conocer en persona lo que se decía en la prensa, o se comentaba en tertulias y ambientes académicos sobre la geografía, el paisaje y su posible origen y antigüedad. Con el correr del tiempo el imaginario social y el refinamiento de un discurso que quedó impreso en narraciones románticas, poesía, artículos, ensayos, memorias y libros, contribuirían a hacer de este nicho geográfico y geológico el primer espacio natural protegido de manera oficial por sus particulares atributos en los tres reinos de la naturaleza, y porque los visitantes sustraían rocas y objetos arqueológicos de pobladores ancestrales del interior de la caverna, bien para sus colecciones o como recuerdo. Era tal la afluencia de personas de todos los estratos sociales, que en 1858 la Sociedad Mexicana de Geografía y Estadística (SMGE) denunciaba que «quienes entraban salían con pedazos de estalactitas»; esta situación los orilló a crear la Comisión de Arqueología, que tuvo entre sus primeros trabajos: «procurar que se reúnan cuantos 
datos sean posibles sobre el estado que guardan los antiguos monumentos del país, que acreditan, así la diversidad de razas que lo han poblado, como su cultura, su civilización y su alta antigüedad» (La Sociedad, periódico político y literario, 6 de julio de 1858, p. 2).

Lo que publicaron los naturalistas, geógrafos y geólogos mexicanos con un valor científico, fue el resultado de programas más o menos institucionales que organizaron la Sociedad Mexicana de Geografía y Estadística (SMGE), el Instituto Médico Nacional y el Instituto Geológico Mexicano, en el último tercio del siglo XIX y a principios del siglo XX. El contenido de los escritos no deja duda del sentido utilitario con el que irremediablemente se acercaron a la caverna, aunque en los espacios de las sociedades científicas se aventuraran otras explicaciones relacionados con el aspecto teórico y los alcances filosóficos de los paradigmas en boga buscando el consenso entre los hombres de ciencia de su pequeña comunidad ${ }^{15}$.

\section{Las cavernas como objeto científico}

Años antes de que los profesionales de la ciencia mexicana concibieran la caverna de Cacahuamilpa como un problema científico, ésta ya había sido explorada con los mismos propósitos por dos expediciones francesas dirigidos por Jean Baptiste Louis, barón de Gros (1793-1870) y Dominik Bilimek (1813-1884), custodio de las colecciones del emperador Maximiliano en su etapa mexicana. Sus resultados terminarían por atraer el interés de la comunidad científica mexicana e internacional. La primera dio a conocer una pintura (figura 2) de la caverna realizada por el propio Gros, en la que la representación del objeto científico quedó a la vista de todos en el año de 1835; la segunda exploró por primera vez la fauna y la flora de su interior. Ambos estudios fueron publicados por la Commision Scientifique du Mexique, durante la intervención francesa (1863-1867), como parte de su programa de investigación (Gros, 1865, p. 137-146; Lara Mimbrera, 1999, p. 165; Trabulse, 1995, p. 36).

Pasados los años inciertos de la intervención norteamericana (1845-1847) y francesa (1863-1867), el maltrecho país había restituido las instituciones republicanas y asegurado un mínimo de certidumbre al mundo académico. A partir de entonces los intereses de la pequeña comunidad científica mayoritariamente residente en la ciudad de México, caminaría de la mano de los gobernantes en las tareas más apremiantes que demandaba la sociedad mexicana: conocimientos y recursos naturales que contribuyeran al desarrollo y a su progreso económico.
Las cavernas de Cacahuamilpa que ya estaban bastante bien posesionadas en el imaginario social de dentro y fuera del país, como muestra de lo inconmensurable de su riqueza, diversidad biológica y belleza paisajística, atrajo el interés del presidente Sebastián Lerdo de Tejada en los días felices de la República Restaurada, que se aprestó a recorrer y a reconocer la zona como un mensaje al mundo civilizado de los nuevos tiempos.

El 15 de febrero de 1874 el presidente Sebastián Lerdo de Tejada salió de México con una comitiva conformada por gobernadores, diputados, secretarios, militares, periodistas y otras personalidades, con rumbo a la gruta de Cacahuamilpa, a donde llegaría el «martes á las ocho de la mañana» y donde permanecería hasta las cuatro de la tarde, hora en que volvería a Tetecala (EI Siglo Diez y Nueve, febrero 15 de 1874, p. 3). Es decir, permanecieron ocho horas en ella. Entre los acompañantes del presidente se encontraban: el periodista de corte liberal Alfredo Bablot (18271892), nacido en Burdeos, Francia, radicado en México a partir de 1849, y redactor del Federalista; Ignacio Manuel Altamirano (1834-1893), intelectual y magistrado de la Suprema Corte, y el naturalista y geólogo Mariano Bárcena (1842-1899), también redactor del Federalista (Bárcena, 1874, p. 7). Los tres también eran miembros de la Sociedad Mexicana de Geografía y Estadística (Morelos, 2012, p. 94-110).

Este viaje tuvo repercusiones en el terreno político que no toca abordar en esta investigación (Barajas Durán, 2005, p. 309), lo que interesa es la discusión que se abrió en la SMGE sobre la exploración de las cavernas, y que comenzó con un telegrama que Alfredo Bablot envió a intelectual e historiador Manuel Orozco y Berra (1816-1881), justo cuando iba de regreso. La discusión se recoge en las actas impresas en el Boletín de la Sociedad Mexicana de Geografía y Estadística. Según refiere el Acta Número 9 de las Sesiones de la SMGE, el 21 de febrero de 1874, en dicho comunicado el periodista expresaba sus impresiones sobre las cavernas, y decía que sus formaciones rocosas indicaban "una antigüedad mucho mayor que la de la creación del mundo, fijada en la Biblia» (Boletín de la Sociedad Mexicana de Geografía y Estadística, 1874, p. 21). Después de la lectura de esta parte del telegrama se desató una discusión en la que intervino principalmente Orozco y Berra, quien ya había visitado las cavernas, a quien esa opinión no le pareció suficientemente fundada. "Habló en seguida del aspecto geológico, e intervinieron Ignacio Ramírez, Manuel Rivera, Ward Pool, Mandred y Rul». 
Figura 2. Caverna de Cacahuamilpa, 1835, pintura realizada por el barón de Gros. «Historia de la espeleología», Web, 2013

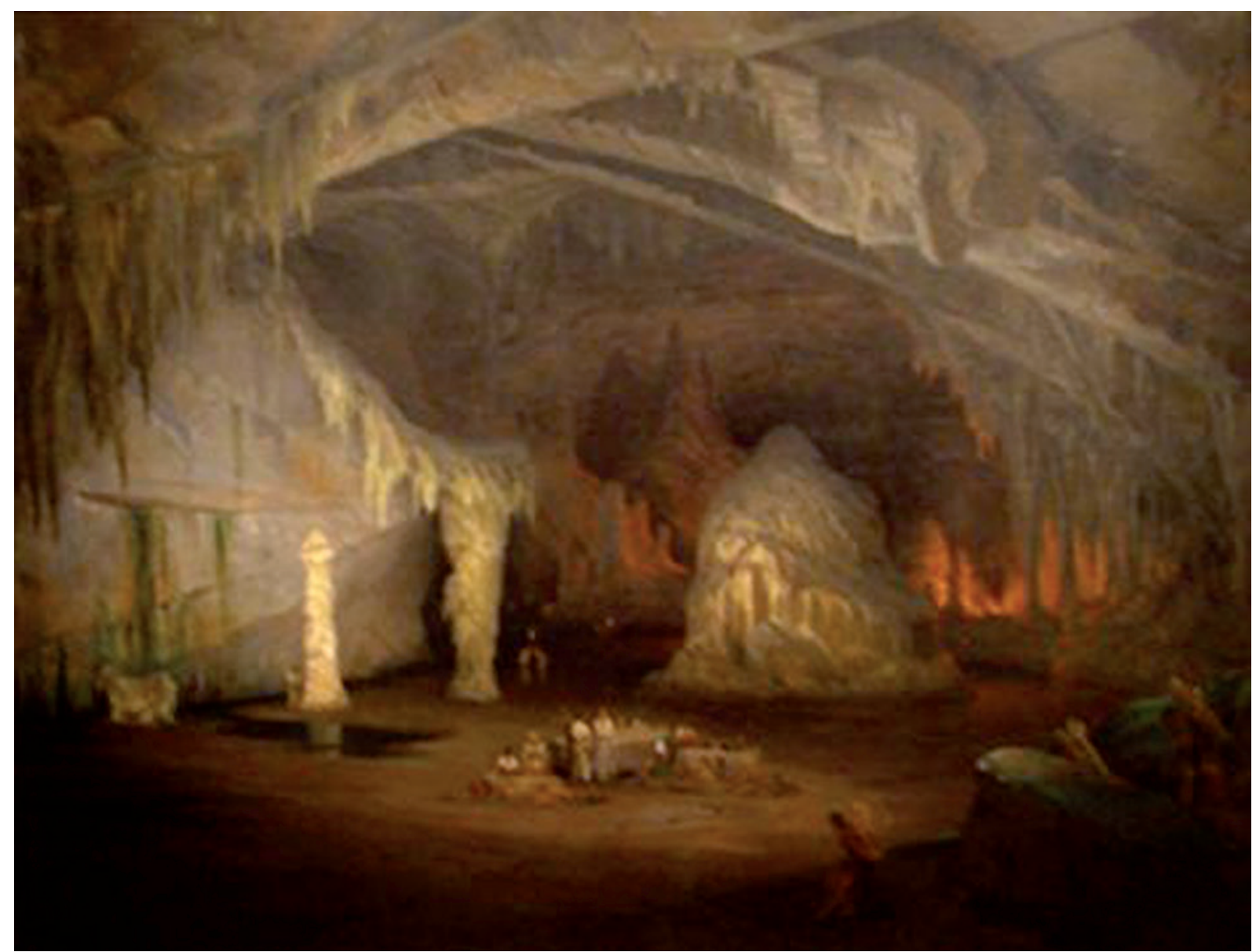

El Acta Número 10 refiere que en la siguiente reunión se presentó el mismo Alfredo Bablot para reiniciar el debate. Respondieron Orozco y Berra, Mariano Bárcena, Ignacio Ramírez (1818-1879) - escritor, poeta, periodista, abogado, político e ideólogo liberal, a la sazón presidente de la Sociedad- y el arquitecto ingeniero Manuel Sánchez Facio (1843-?). Antonio García Cubas (1832-1912), intelectual y geógrafo, leyó una parte de su memoria sobre las grutas, y dado que la reunión se prolongaba, quedó en terminar de leerla en la siguiente sesión. No obstante, los miembros de la SMGE tomaron el acuerdo de preparar una expedición científica a la brevedad, pero con los recursos y el tiempo suficiente para hacer estudios series y bien fundamentados sobre los temas debatibles. Con respecto a la expedición, las actas de sesiones siguientes mencionan los preparativos, los fondos, los miembros: Gumesindo Mendoza, Francisco Jiménez, Lobato, Eufemio Mendoza, Vicente Reyes, Santiago Ramírez, Díaz Aguirre, Amado Chimalpopoca, Hill, Celso Muñoz y un fotógrafo (Boletín de la Sociedad Mexicana de Geografía y Estadística, 1874, p. 21).
Pero el 30 de marzo del mismo año Ignacio M. Altamirano publicó en El Federalista una carta dirigida a Alfredo Bablot, donde explicaba que la sociedad había decidido posponer el viaje por varios motivos, entre ellos la ausencia de Mariano Bárcena y del fotógrafo; la falta de luces adecuadas para el interior de la caverna; el compromiso de buena parte de los comisionados con sus respectivas cátedras - varios daban clase en distintas instituciones-. Faltaban también las secciones para formar el plano topográfico exterior y la que estudiaría la parte hidrográfica, entre lo más destacado (El Federalista, 29 de marzo de 1874 , p. 1).

La documentación nos dice que no se realizó la expedición. Las razones pueden ser muchas. Lo que queda más claro es que los que iban a participar en la expedición científica se sumaron a otros proyectos que sí eran oficiales, como la comisión encargada del viaje a Japón para medir el paso de Venus por el Sol, en la cual también participó Francisco Jiménez, o la comisión para el estudio de los temblores de Jalis- 
co ocurridos en febrero del siguiente año, en la cual participó Mariano Bárcena. Ambos proyectos diferían del de Cacahuamilpa en tanto que serían de utilidad al país. El primero porque permitiría a México sumarse en una investigación de carácter internacional, en la que se esperaba se hiciese una contribución importante. Y el segundo, la comisión para estudiar los temblores aportaría datos sobre las causas de dichos movimientos telúricos y sus posibles consecuencias (Moreno Corral, 1986; 1875).

En todo caso, la discusión que tuvo lugar en la SMGE entre febrero y marzo de 1874, después del viaje con el presidente Sebastián Lerdo de Tejada, pone en dimensión las preocupaciones teóricas y filosóficas de los mexicanos por temas de frontera en el campo de la geología. Manuel Orozco y Berra había realizado una exploración de las cavernas en 1847 y publicado sus resultados en 1855, en el apéndice del Diccionario Universal de Historia y de Geografía, del cual fue coordinador. Comenzó por definir que se trataba de una caverna, no de una gruta ni de una cueva:

Aunque el nombre de gruta se emplea comúnmente como sinónimo de caverna, se distingue ésta de la primera por la gran estensión y diversas estancias o salones que presenta, en lugar que la gruta se reduce á un salón ó estancia, las más veces no muy grande.

Tampoco debe confundirse la caverna con la cueva, porque ésta se considera como obra artificial y la caverna es una cavidad natural en el interior de la Tierra, que presenta cierta estensión y que se compone ordinariamente de una serie de estrecheces y ensanches, esto es, de una especie de estancias ó salones más o menos vastos, que se comunican por pasadizos más ó menos estrechos.

En cuanto a la descripción geológica que realiza del lugar, el geógrafo menciona el método actualista como el camino para explicar su formación:

No es fácil esplicar [sic] de un modo enteramente satisfactorio el origen y formación de estas cavernas; pero examinando y fijando la observación en los fenómenos actuales, se dan esplicaciones [sic] que convencen más, por estar fundadas en hechos y no en sistemas caprichosos (Orozco y Berra, 1855, p. 415-418).

Por otra parte, puede verse su interés por encontrar fósiles -instrumentos para datar los estratos-, y sugiere que se realicen estudios paleontológicos del lugar. Es menester comentar que dado que la exploración promedio a esta caverna se realizaba en ocho horas - después de las cuales había que regresar para evitar pasar la noche en ellas o en el peligroso camino frecuentado por asaltantes-, Orozco y Berra no contó con el tiempo necesario para hacer estudios más profundos. Pero sí señala los rumbos para exploraciones posteriores: la búsqueda de fósiles, la determinación de su origen y la investigación relacionada con la datación del planeta. ¿Cuántos años tiene la Tierra?, fue la pregunta que lanzó a sus conciudadanos.

Antonio García Cubas, al igual que Orozco y Berra, era geógrafo, pero había realizado trabajos geológicos anteriormente, al igual que otros ingenieros contemporáneos (Almaraz, 1866, p. 13-17) ${ }^{16}$. El texto que entrego a la SMGE refiere, después de describir la topografía, la geografía, los sistemas de vegetación y fauna, sus aspectos demográficos, sociales y económicos de la región, que las bóvedas de la caverna son de piedra caliza, y que las ideas sobre el origen de su formación se encuentra dividida, dado que "unos la atribuyen a la acción de las aguas y otros a la plutónica». Afirma que la existencia de dos ríos internos es la causa para que se crea que el agua ha sido el principal agente de su formación, pero él, apoyado en la observación de los terrenos adyacentes - que tienen «dislocadas y metamorfoseadas las capas calizas»-, cree que el origen fue una dislocación violenta del terreno (García Cubas, 1874, p. 147-149).

El Acta número 11 reseña que tocó el turno a Mariano Bárcena leer su informe sobre la exploración geológica de Cacahuamilpa. Después de una descripción mineralógica del camino y de la caverna, en la que describe los terrenos calizos que conforman el lugar, prosigue con el análisis geológico, para «determinar las épocas relativas de su formación y de los fenómenos que las han alterado» (Bárcena, 1874, p. 14).

Bárcena en su estudio sobre Cacahuamilpa utiliza el término metamórficas en el mismo sentido que Lyell ${ }^{17}$, al explicar la existencia de pizarras arcillosas y las masas calcáreas en el terreno de la zona, «que en un principio fueron también sedimentarias», ahora "se encuentran trastornadas y removidas en diversas direcciones por la acción de las rocas ígneas». Y pese a que solamente las observó unas horas, se formó «una idea muy general de sus caracteres» [sic], que no le impidió datarlas por la presencia de «conchas de nerinea» y otros restos fósiles paleontológicos, «como perteneciente al fin del período jurásico y principio del cretáceo» (Bárcena, 1874, p. 17).

Después de explicar que los pórfidos traquíticos hicieron «su aparición en el tiempo cenozóico, tanto en América como en el antiguo continente», refiere «con bastante fundamento que la caverna se formó 
en el período terciario» (Bárcena, 1874, p. 21) ${ }^{18}$. Para ese entonces, el periodo denominado por Lyell como Terciario había sido rebautizado por Phillips como Cenozoico (todavía no se había creado el Cuaternario) (Fernández-López, 1997, p. 79-106). Por otra parte, Bárcena definió también los aspectos que debían investigarse en la expedición que organizaba la SMGE, pero como ya dijimos, no fue posible:

1. Obtener conocimiento topográfico de la montaña donde se encontraba la caverna.

2. Consultar los estudios realizados en el mineral de Taxco, para buscar los principales agentes del levantamiento de sus montañas.

3. Realizar un estudio topográfico de la caverna.

4. Realizar también un estudio geológico de la caverna y de las montañas ya referidas.

5. Finalmente, hacer algunas observaciones meteorológicas para compararlas con las que se han determinado en algunas grutas ya estudiadas (Bárcena, 1874, p. 13).

En resumen, sobre las exploraciones a Cacahuamilpa en el siglo XIX puede observarse que, desde su descubrimiento en 1834, varias personas acudieron a explorar estas cavernas. Entre ellas personalidades de la política, artistas que intentaron reproducir su majestuosidad, hombres de ciencia que trataron de ingresarlas en el inventario de la República mexicana al nombrarlas, definirlas, describirlas y explicar su origen. También puede apreciarse que del encuentro con esta maravilla de la naturaleza se plantearon más preguntas: al adentrarse en sus pasillos, en sus galerías, al recorrer los intrincados laberintos se cuestionaron: ¿cuántos años tiene la Tierra? Formulada por Manuel Orozco y Berra, quien la lanzó al aire en 1855 , esta pregunta es una muestra de que los hombres de ciencia mexicanos también se planteaban cuestiones filosóficas, si bien es verdad que no dispusieron de los recursos o del apoyo para comprobar sus hipótesis.

Que Alfredo Bablot, un periodista, la haya vuelto a formular en 1874, cuando recién el debate sobre la edad de la Tierra había cobrado nuevos bríos gracias a la intervención del famoso físico británico William Thomson, es indicativo de que en la prensa científica se seguía este debate, como es el caso del Boletín de la SMGE.

En esta aproximación a los primeros trabajos de índole científica sobre las cavernas de Cacahuamilpa, puede observarse que la visión de cada explorador fue distinta. Para Orozco y Berra era importante ingresarlas en el inventario de la República mexicana, por lo cual las nombró correctamente, tanto en general con la denominación de cavernas, como en lo específico, en lo tocante a la nominación de cada galería. Describió el tramo recorrido e incluso trató de explicar su origen.

La exploración de Bilimek, optuvo por primera vez una visión integrada de la fauna y flora dentro de ellas, para catalogarla en el acervo del Museo Nacional. A pesar de presentar su trabajo sobre las cavernas en el seno de una discusión sobre la edad de la Tierra, el material que García Cubas preparó no trataba de responder la pregunta señalada, sino más bien su valor residía en los aspectos geográficos.

Mariano Bárcena clasificó la formación de las calizas en el periodo terciario. Si bien no se tenía bien definida la cronología de cada periodo, sí representa un aporte para el estudio del suelo mexicano. Sin embargo, debe deducirse que se esperaba que la futura expedición, mejor organizada, pudiera ayudar a los miembros de la Sociedad Mexicana de Geografía y Estadística a realizar alguna aportación de mayor importancia en la discusión que se tenía sobre este tema.

Pero fue pospuesta y finalmente cancelada la expedición de la Sociedad Mexicana de Geografía y Estadística, en un periodo presidencial donde se apoyó la investigación científica - baste recordar que ese mismo año se realizó la expedición a Japón para medir el paso de Venus por el Sol, encabezada por el geógrafo Francisco Díaz Covarrubias y en la cual también participó Francisco Jiménez, considerado para integrar la comisión a las grutas de Cacahuamilpa-. Al respecto, es preciso recordar que la SMGE ya había perdido su papel principal como institución científica, a causa de motivos políticos y con el nacimiento de la Sociedad Mexicana de Historia Natural en 1868, que poco a poco fue encargándose de la investigación geológica del país (Uribe, 2013a; 2013b).

Expediciones posteriores se realizaron, pero ya tuvieron otros objetivos. La organizada por el Instituto Médico Nacional fue más bien de recolección de especies vegetales, para el estudio de las aguas y en general para aspectos relacionados con la medicina. El que a inicios del siglo XX el Instituto Geológico Nacional y la Sociedad Geológica Mexicana haya retomado las exploraciones a Cacahuamilpa - concretamente en 1909-, manifiesta el interés de la comunidad geológica por estudiarlas y posi- 
bilita observar el conocimiento acumulado en más de 50 años. Sin embargo, esto no subsana la suspensión de la expedición de 1874, puesto que los mexicanos perdieron la oportunidad de entrar en una discusión sobre el tema, que quizá les hubiera dado la posibilidad de tratar con sus pares europeos sobre un aspecto filosófico de la Geología como la edad de la Tierra, o sobre los procesos de formación de las cavernas o los fósiles contenidos en ellas para abordar otros problemas que para entonces ya estaban planteados como la evolución de las especies y la selección natural. Aspectos en que se encontraban interesados y que tal vez les hubieran permitido realizar investigación «de punta» sobre los sistemas geológicos y sus métodos de investigación (Valdivia, 2013).

Con esto queda en evidencia el grado de afectación que los factores sociales ejercen sobre la investigación científica, y es también un ejemplo de cómo ésta no puede ser sustraída de su contexto. Aunque algunos de los geólogos mexicanos que originalmente iban a formar parte de la expedición volvieron después a las grutas, el grupo ya se había disgregado y la discusión había perdido su fuerza inicial.

\section{NOTAS}

1 Este escrito forma parte de una investigación más amplia que lleva por título: Las cavernas de Cacahuamilpa en el debate geológico de México, vinculada al proyecto científico que dirige el Dr. Miguel Ángel Puig-Samper en el Instituto de Historia del CCHS/CSIC: Ciencia y espectáculo de la Naturaleza. Viajes cientificos y museos de Historia Natural. Referencia: HAR2013-48065-C2-2-P. Madrid, España, 2015-2016.

2 Esto no quiere decir que sean las únicas referencias existentes, pero creemos que es una muestra representativa de lo publicado sobre el tema.

3 Mariano Galván fue un reconocido impresor de la época en la ciudad de México, que adquirió fama por la impresión de Calendarios o Almanaques, en los que introduje diversos recursos técnicos y temas de interés para un público más amplio de lectores. De ellos destacan: Calendario de las señoritas mexicanas, 1839-1843 y Calendario Manual, 1826, pero a partir de 1858 a la fecha, se le conoce como Calendario de Mariano Galván Rivero. Consúltese: Clark de Lara y Speckman Guerra, 2005.

4 Debido a la importancia que tuvieron, consideramos que al anterior listado le hacen falta la expedición de Dominik Bilimek en 1867, la de los comerciantes norteamericanos a inicios de 1879, y la que se realizaría con posterioridad a su viaje por los expedicionarios del Instituto Médico Nacional en 1892.

5 Cabe destacar que dicho registro no incluye monografías ni revistas como el Boletín de la Sociedad Mexicana de Geografía y Estadística, La Naturaleza, Revista de la Sociedad Mexicana de Historia Natural, El Estudio, Semanario del Instituto Médico Nacional.

6 Para la elaboración de esta gráfica se eliminaron registros dobles de un mismo artículo publicado en el mismo medio y el mismo día, no así de aquéllos que se repetían en distinto día o año. Cabe destacar que no incluye resultados que hablan de forma tangencial o indirecta de las grutas, como algunos noticias sobre la visita del presidente Sebastián Lerdo de Tejada y que no incluían la palabra "Cacahuamilpa".

7 El Siglo Diez y Nueve, marzo 4 de 1874, p. 2.

8 El Siglo Diez y Nueve, marzo 30 de 1874, p. 3.

9 El Siglo Diez y Nueve, octubre 9 de 1879, p. 3.

10 La Convención Radical Obrera, julio 5 de 1896, p. 3; La Voz de México, octubre 27 de 1896, p. 3.

11 La Convención Nacional Obrera, julio 5 de 1896, p. 3.

12 El Padre Cobos, Tomo I, núm. 24, 13 de mayo de 1869.

13 Al tener el mismo apellido que José Nosari, el primer director de la Compañía Explotadora de las Grutas de Cacahuamilpa S. A. (La Convención Radical Obrera, julio 19 de 1896:2), suponemos que son parientes, pero falta abundar en la investigación.

14 Pese a existir una traducción al castellano, preferimos utilizar el lenguaje original en que fue escrito.

15 Otras cavernas estudiadas por los mexicanos en el siglo XIX fueron: la caverna Ojo de Agua, en 1887 y la gruta El Encanto, en Guerrero, en 1890. Véase: Memoria del Gobierno del Estado de Guerrero, 1890, p. 185-187; Villada, 1887, p. 81-85.

16 Entre sus trabajos geológicos podemos mencionar, el resultado de la Comisión Científica a Metlatloyuca, encabezada por Ramón Almaraz, Guillermo Hay y Antonio García Cubas, que debía "reconocer el camino entre Tulancingo y Huachinango para examinar los terrenos baldíos y hacer un croquis de ellos para saber de su situación y superficie". En el Croquis del camino de Tulancingo a la Mesa de Coroneles incluyeron el corte geológico teórico, que menciona los se- 
dimentos terciario, cretácico, basáltico, volcánico y moderno. Asimismo, recogieron rocas de cada capa descrita.

17 Habrá que recordar, sin embargo, que el británico publicó por primera vez sus obras en la década de los treinta del siglo XVIII. Véase al respecto, Lyell, 1837, p. 184-186.
18 Se trata del periodo anterior al Cuaternario, que comprende hasta nuestros días. Charles Lyell subdividió el periodo terciario en tres: Eoceno, Mioceno y Plioceno, y concluyó que las formaciones calizas pertenecían al terciario reciente. Sin embargo, no planteó la cronología para cada uno. Lyell, 1837.

Cañas, Eugenio J. (1887), "De México a Cacahuamilpa”. En: Robles, Pablo, Los plateados de Tierra Caliente, Cuernavaca, Biblioteca Virtual Antorcha, [en línea], disponible en: http://www.antorcha.net// index/biblioteca.html [consultado 13/11/2012].

Carabés, Celia Miranda (1998), "Estudio preliminar". En: La novela corta en el primer romanticismo mexicano, segunda edición, México, Coordinación de Humanidades, Instituto de Investigaciones Filológicas de la UNAM.

Collet Sedola, Sabina (1995), “Historia y pedagogía: Cristóbal Colón de Elvira Nosari (s. XIX)". En: Actas del XII Congreso de la Asociación Internacional de Hispanistas, Tomo VI, Estudios Hispanoamericanos I, 21 al 26 de agosto, Birmingham, Hobs The Printers Ltd., pp. 130-137, [en línea], disponible en: http://cvc.cervantes.es/literatura/aih/pdf/12/ aih_12_6_019.pdf [consultado 2/2/2014].

Cortés Zavala, María Teresa y José Alfredo Uribe Salas (2014), "Ciencia y Economía del Guano: La Isla Mona en Puerto Rico, siglo XIX", En: Memorias. Revista digital de Historia y Arqueología desde el Caribe, Colombia, pp. 81-106, doi: http://dx.doi.org/10.14482/memor.22.5948

Cuéllar, José Tomás (1856), "En la caverna de Cacahuamilpa". En: Obras poéticas de..., Imprenta de Ignacio Cumplido, pp. 172-177.

Cumplido, Ignacio (ed.) (1874), “Noticias nacionales y extranjeras". En: El Siglo Diez y Nueve, 15 de febrero, Octava época, Año XXXIII, Tomo 56 (10631), p. 3.

Fernández-López, Sixto (1997), “Fósiles de intervalos sin registro estratigráfico: una paradoja geológica". En: Aguirre, Emiliano et al. (coords.), Registros fósiles e historia de la Tierra, Madrid, Editorial Complutense, pp. 79-106.

Fidel (1845), “Ojeada a varios lugares de la República. Un paseo a Cuernavaca, por..., el mes de octubre de 1845". En: Revista Científica y Literaria de Méjico, publicada por los antiguos redactores del Museo Mejicano, Tomo I, México, Imprenta Litográfica calle de las Palmas, pp. 111-127.

Flores, Teodoro (1909), “La caverna de Cacahuamilpa, por el Ingeniero de Minas...", Boletín de la Sociedad Geológica Mexicana, Tomo VI.

Galván, Mariano (1838), "La Caverna de Cacahuamilpa". En: Mariano Galván (ed.), Calendario de las Señoritas Megicanas para el año de 1838, México, pp. 159-183. 
García Cubas, Antonio (1874), "Una excursión a la caverna de Cacahuamilpa". En: Escritos diversos de 1870 a 1874, México, Imprenta de Escalante.

García Cubas, Antonio (1904), El libro de mis recuerdos, narraciones históricas, anecdóticas y de costumbres mexicanas anteriores al actual estado social. Ilustradas con más de trescientos fotograbados. México, Imprenta de Arturo García Cubas, Hermanos Sucesores.

Gros, barón (1865), Renseiguements destinés aux voyageurs qui auront à étudier les monuments auciens situés dans les environs de Mexico, Arch. Commissions Scientifique du Mexique 1, pp. 137-146.

Gunn, John (ed.) (2004), Encyclopedia of Caves and Karst Science. New York, Taylor \& Francis Group.

"Historia de la espeleología", [en línea], disponible en: Seduma, http://www.seduma.yucatan.gob.mx/ cenotes-grutas/ historia-espeleologia.php [consultado 30/6/2013).

Humboldt, Alexander von (2002), Ensayo político sobre el reino de la Nueva España, Colección Sepan cuántos..., sexta edición. México, Porrúa.

Informe y colección de artículos relativos a los fenómenos geológicos verificados en Jalisco en el presente año y en épocas anteriores. Edición oficial, Tomo I, Guadalajara, Pip. de S. Banda, calle de la Maestranza, 1875.

Instituto Nacional de Estadística, Geografía e Informática (INEGI), División territorial de los Estados Unidos Mexicanos de 1810 a 1995, México, 1997.

Iturriaga de la Fuente, José N. (1992), Escritos mexicanos de Carlota de Bélgica, México, Banco de México.

Landesio, Eugenio (1868), Excursión a la caverna de Cacahuamilpa y ascensión al cráter del Popocatépetl. México, Imprenta del Colegio de Tecpam.

Lara Mimbrera, Iván (1999), Reacciones, colaboraciones y proyectos científicos. Los ingenieros de Minería durante la Intervención Francesa y el Segundo Imperio en México (18621867), Tesis de Licenciatura. México, Universidad Autónoma Metropolitana, Unidad Iztapalapa.

Lyell, Charles (1837), Principles of Geology, Vol. III, Fifth edition. London, John Murray.

Lyell, Charles (1847), Elemento de Geología. España, Imprenta de Don Antonio Yanes.

Martínez Andrade, Marina (2008), "Guillermo Prieto, viajes y escritura", Iztapalapa, Revista de Ciencias Sociales y Humanidades, 29 (64-65), pp. 277-299.

Martínez Andrade, Marina (2011), "El manual del viajeros de Marcos Arroniz", Literatura Mexicana, 22 (1), Portal de Revistas Científicas y Arbitradas de la UNAM, UNAM, México, pp. 75-97.
Memoria del Gobierno del Estado de Guerrero (1890), "Descripción de la gruta del 'Encanto' ubicada en el Coquillo, perteneciente á la Municipalidad de San Marcos en el Distrito de Tabares", En: Memoria del Gobierno del Estado de Guerrero, México, Imprenta de Gobierno, pp. 185-187.

Morelos Rodríguez, Lucero (2012), La geología Mexicana en el siglo XIX. Una revisión histórica de la obra de Antonio del Castillo, Santiago Ramírez y Mariano Bárcena. México, Plaza y Valdés Editores.

Moreno Corral, Marco Arturo (1986), Odisea 1874 o el primer viaje internacional de científicos mexicanos. México, SEP.

Nosari, Elvira (1899), "Un viaje a Cacahuamilpa, primera parte”, El Mundo, México, mayo 21, pp. 6-7.

Nosari, Elvira (1899), Una visita a las grutas de Cacahuamilpa. Imprenta y Casa Editorial de J. M. Mellado.

Orozco y Berra, Manuel (coord.) (1855), Apéndice al Diccionario General de Historia y de Geografía, colección de artículos referentes á la República Mexicana, Tomo I, VIII de la obra. México, imprenta de J. M. Andrade y F. Escalante.

Perales Ojeda, Alicia (2000), Las asociaciones literarias mexicanas, segunda edición. México, UNAM.

Pierini, Margarita (1990), Viajar para (des)conocer, Isidore Löwenstern en el México de 1838. México, Universidad Autónoma Metropolitana, Unidad Iztapalapa.

Piho, Virve (1991), "La organización eclesiástica de la Nueva España durante los siglos XVI y XVII", Estudios de Historia Novohispana, 10, pp. 11-30.

Quiñónez, Isabel (2005), “De pronósticos, calendarios y almanaques". En: Belem Clark de Lara y Elisa Speckman Guerra, La república de las letras. Asomos a la cultura escrita del México decimonónico: Publicaciones periódicas y otros impresos, vol II. México, Universidad Nacional Autónoma de México, pp. 331-351.

Robelo, Cecilio A. (1886), "Los estados mexicanos. Cacahuamilpa", La Patria, Diario de México, Año X, núm. 2653, 7 de febrero, México, p. 2.

Robelo, Cecilio A. (1886), "Los estados mexicanos. Cacahuamilpa", La América, Año XXVII Núm. 2, 28 de enero, Madrid, pp. 14-15.

Trabulse, Elías (1995), Arte y ciencia en la historia de México. México, Fomento Cultural Banamex.

Uribe Salas, José Alfredo (2008), Empresas ferrocarrileras, comunicación interoceánica y ramales ferroviarios en Michoacán, 1840-1910. México, Universidad Michoacana de San Nicolás de Hidalgo.

Uribe Salas, José Alfredo (2013), "La Naturaleza and the Mexican Geologists in the second half of the nineteenth century", 
De Re Metallica, 21, Sociedad Española para la Defensa del Patrimonio Geológico y Minero, Madrid, pp. 59-68.

Uribe Salas, José Alfredo (2013), “De la aclimatación de la Mineralogía al desarrollo de la Geología o la promoción de conocimientos para el desarrollo de México, Siglo XIX". En: Luis Calvo, Álvaro Guirón Sierra y Miguel Ángel Puig Samper (eds.), Naturaleza y Laboratorio, Barcelona, España, CSIC, 2013, pp. 117-142
Valdivia Moreno, Laura (2013), Ciencias de la Tierra en México (18461906). Teoría y práctica científica, (Tesis de maestría en Historia), Morelia, Universidad Michoacana de San Nicolás de Hidalgo.

Villada, Manuel M. (1887), "La caverna de Ojo de Agua”. En: La Naturaleza, 2a. s. I., pp. 81-85, 2 láms.

Zarco, Francisco (1852), "Viaje a Cacahuamilpa". En: Presente Amistoso dedicado a las Señoritas Mexicanas, México, Imprenta litográfica y tipográfica del I. Cumplido. 